\title{
Regional identity of personality: childhood experience
}

\author{
Lyudmila Maksimova ${ }^{1 *}$, Ravil Valiev ${ }^{1}$, Natalia Ruzhentseva ${ }^{1}$, and Tatyana Valieva ${ }^{2}$ \\ ${ }^{1}$ Ural State Pedagogical University, Kosmonavtov st., 26, Yekaterinburg, Russia, \\ ${ }^{2}$ Ural State Medical University, Repina st., 3, Yekaterinburg, Russia
}

\begin{abstract}
The paper is devoted to studying regional identity as a psychological interconnection with the territory of residence.The objective of the research is studying the peculiarities of an inhabitant's mental representation of the childhood experience of this psychological interconnection. The research is based on the narrative method. As a result of factor analysis, the following six factors were specified in the psychological structure of the regional identity experience representation: "Activity", "Estrangement", "Readiness", "Satisfaction", "Regulativity", "Modality". Proceeding from the two samples compared, the following peculiarities of the childhood regional identity experience were revealed. Those who experienced regional identity in the childhood are more deeply involved in the experience, without isolating themselves from the internal and external circumstances that entailed the experience; they demonstrate a more positive attitude and are open to such experience. It appears that regulativity of the regional identity experience serves as a resource for its formation in youth. The obtained results can create the basis of a psychology pedagogy program of children's regional identity formation (including migrant children) realized in educational organizations.
\end{abstract}

\section{Introduction}

\subsection{Relevance of research on regional identity}

The ethnic map of the most of modern states is characterized with a high level of variety and ethno-religious heterogeneity of the indigenous populations. However, the current situation is specific due to intensification of the migration processes leading to co-residence of natives with a considerable number of newcomers in one and the same territory that makes a search for psychological mechanisms forming a regional community especially significant. According to a number of studies, studying a native's psychological connection to the region inhabited might become an approach to the problem solution. The connection in question to the fullest extent possible is expressed in the concept "regional identity".

\subsection{What is regional identity?}

Being a cross-disciplinary one, the concept of regional identity in Russia is regarded within sociology, political science, geography, cultural studies $[1,2,6,7,12,16,18,19,22,24]$.

\footnotetext{
*Corresponding author: maximova70@mail.ru
} 
Psychological researches of regional identity are generally focused on the subjective interconnection between the personal internal space and the external space of a person's existence $[11,23]$. The psychological connection of a person to the external environment in English-language scientific literature is termed as "place identity", "sense of place", "place attachment" $[14,17]$. By the majority of the researchers, regional identity is termed as a type of social identity focused on a geographically localized territory. Holders of regional identity take a complex of emotional experiences concerning the region of their residence and correlate their life goals, values and activities with social and cultural processes occurring there.

\subsection{Why should childhood experience of personal psychological interconnection with the region of residence be studied?}

The present research is based on the following assumptions. Firstly, the psychological interconnection with the region of residence is based on an individual experience of a significant event when a person perceives him or herself as an inhabitant of the region for the first time; secondly, such experience can be endured by the person at different stages of life that influences the varieties of the formed identity, both personal and regional, psychological content. Thirdly, identification of the peculiarities specific for mental representation of such individual experience of a significant event allows to reveal the formed regional identity psychological content depending on the stage of human life when the experience was taken - childhood, youth or maturity. The obtained results might create the basis of a psychology and pedagogy program of children's regional identity formation (including migrant children) realized in educational establishments.

\section{Problem Statement, research questions and purpose of the study}

Identification of the childhood conditions of regional identity formation. What is the psychological content of the regional identity experience mental representation?

What are the differences in the regional identity content in regard to experiencing the interconnection with the territory of residence in childhood and youth? Identification of the peculiarities specific for the inhabitant's mental representation of the childhood experience of psychological interconnection with the territory of residence.

\section{Research Methods}

\subsection{Subjects (cases)}

The study subjects were young people at the age of 20-22 years living in the territory of Sverdlovsk region, Russian Federation.

\subsection{Procedure}

As the research of regional identity is generally focused on studying the experience which has influenced the personality's awareness of psychological interconnection with the territory of residence, the narrative method is considered the most suitable one. This method is currently applied to analyze not only literary works but cinema, historical, judicial, law, musical medicine and other discourses as well.

From our point of view, studying regional identity corresponds to the narrative area devoted to personal experience. The narrative analysis techniques allow to reveal the specific features of the subject's experience representation [3]. Thus, on creating the respective conditions, there is the opportunity to reveal the substantial and procedural constituents of the personal experience of regional identity [21]. Representation of the 
experience in a narrative provides its interpretation and ordering [1]. The integrity of the experience at the same time is provided due to embodiment of a direct experience in cultural signs and symbols [4].

The respondents were offered to write a story describing a life situation when they perceived themselves as the inhabitants of Sverdlovsk region surely specifying: a) when and where the event which entailed the experience happened, b) what was happening in the beginning of the event (what was being said and done by the participants), c) what happened next (what was said and done by participants of the event later on), d) what feelings you had at the moment, e) what thoughts were evoked, e) what happened in the end. Processing of the obtained narratives was carried out by the content analysis method enabling us to fix the representative features of an individual experience of regional identity. The following criteria were developed for this purpose.

1. The narrative criteria (representation of the time sequence, place and participants).

2. The plot (the actants, the time occurrence, the substantive content of the event).

3. Representation of the plot (the subject and the form of the activity represented, attitude to the event, modality of the event representation).

4. Representation of the experience (attitude to the identity experience; evaluation of the experience completeness; description of psychological states; the content of the story end fixation).

Exploratory factor analysis by the principal component method with rotation in "Varimax raw" in the STATISTICA program was applied to the information obtained in order to outline the component structure of the regional identity experience; specification of the differences in the regional identity content determined by temporal localization of the experience in childhood or youth was carried out by means of Mann - Whitney U-test.

\section{Findings}

Processing of the obtained narratives by the content analysis method revealed 99 variables which were subjected to exploratory factor analysis. As a result, the 6-factor structure of a significant event experience which has influenced formation of the regional identity (Table 1) was received. The general dispersal percent of the factorial structure is $51 \%$ that is sufficient [15], high reliability of the factors was proved by N.G. Lewandowski's method [13]. Factor analysis casts a glance behind the curtains of what is immediately measured and seeks to define the actual factors underlying the basics of the phenomenon. The principal aim of factor analysis consists in identification of the hypothetical factors through a significant amount of experimental datax [20]. One of the principal objectives is interpretation of the factors. Highly loaded variables are interpreted within each of the factors. Negative factor loading of a variable doesn't designate the feature as a negative one. It only means that the feature is inversely related to the overall factor loading and acts as a pole in the factor continuum. "Each factor is given a name generalizing the meaning of the variables included" [15].

Table 1. The experience of regional identity factor structure

\begin{tabular}{|l|l|c|}
\hline № & \multicolumn{1}{|c|}{ Factor name and the variables determining its content } & Loading \\
\hline \multicolumn{2}{|c|}{ Factor 1. Activity } \\
\hline 1. & Determination as a conative component of the personality & 0,77 \\
\hline 2. & The subject's activity & 0,75 \\
\hline 3. & Incomplete experience & 0,66 \\
\hline 4. & Neutral attitude to the experience of identity & 0,61 \\
\hline 5. & Inspiration as a state of the personality satisfaction & 0,57 \\
\hline
\end{tabular}




\begin{tabular}{|c|c|c|}
\hline 6. & Disappointment as a state of the personality frustration & 0,54 \\
\hline \multicolumn{3}{|c|}{ Factor 2. Estrangement } \\
\hline 1. & Negatively completed experience & 0,76 \\
\hline 2. & Daily routine activities are described within the event & 0,64 \\
\hline 3. & Isolation as a way to assimilate the event & 0,61 \\
\hline 4. & Attitude as a way of fixation of the story ending & 0,59 \\
\hline 5. & The actants' activity & 0,50 \\
\hline \multicolumn{3}{|c|}{ Factor 3. Readiness } \\
\hline 1. & Emotional stress as a state of the personality psychological tension & 0,72 \\
\hline 2. & Enthusiasm as a state of the personality motivation & 0,71 \\
\hline 3. & Pro-active attitude to the event & 0,56 \\
\hline 4. & Fright as a state of the personality suspense & 0,56 \\
\hline 5. & Positive cognitive attitude to the identity experience & 0,56 \\
\hline \multicolumn{3}{|c|}{ Factor 4. Satisfaction } \\
\hline 1. & Positively completed experience & 0,78 \\
\hline 2. & State as a way of fixation of the story ending & 0,67 \\
\hline 3. & Positive personal attitude to the identity experience & 0,62 \\
\hline 4. & The region of residence as the place where the event occurred & 0,59 \\
\hline 5. & Integration as a way to assimilate the event & 0,58 \\
\hline \multicolumn{3}{|c|}{ Factor 5. Regulativity } \\
\hline 1. & Health sphere activities are described within the event & 0,76 \\
\hline 2. & A rule as a way of fixation of the story ending & 0,74 \\
\hline 3. & The season is specified & 0,62 \\
\hline 4. & Disappointment as a state of the personality frustration & 0,59 \\
\hline 5. & Astonishment as the personality cognitive state & 0,59 \\
\hline 6. & Absence of specified time in the description of the event & $-0,53$ \\
\hline \multicolumn{3}{|c|}{ Factor 6. Modality } \\
\hline 1. & Reverie as a state of the personality anticipation & 0,70 \\
\hline 2. & Cognitive modality of the event representation & 0,64 \\
\hline 3. & Ural federal district - the border of the region & 0,63 \\
\hline 4. & Disappointment as a state of the personality frustration & 0,51 \\
\hline
\end{tabular}

After specification of the factor structure of the regional identity experience each subject's individual points for each of the factors were deduced. All the subjects were divided into two groups depending on the life stage when the experience occurred childhood or youth. The differences in the regional identity content were found by means of Mann - Whitney U-test (Table 2).

Table 2. The differences in the regional identity experience content depending on the life stage the experience occurred

\begin{tabular}{|l|l|l|l|l|l|}
\hline Factor name & $\begin{array}{l}\text { Sum of the } \\
\text { «Childhood }\end{array}$ & $\begin{array}{l}\text { Sum of the } \\
\text { «Youth }\end{array}$ & $\begin{array}{l}\text { Empirical } \\
\text { criterion, } U\end{array}$ & $\begin{array}{l}\text { Standardize } \\
\mathrm{d} \text { criterion, },\end{array}$ & $\begin{array}{l}\text { Significance } \\
, p\end{array}$ \\
\hline
\end{tabular}




\begin{tabular}{|l|c|c|c|c|c|}
\hline & $\begin{array}{l}\text { experience» } \\
\text { group ranks } \\
(\mathrm{n}=34)\end{array}$ & $\begin{array}{l}\text { experience» } \\
\text { group ranks } \\
(\mathrm{n}=28)\end{array}$ & Z & & \\
\hline Activity & 1063,00 & 890,00 & 468,00 & $-0,11$ & 0,92 \\
\hline $\begin{array}{l}\text { Estrangemen } \\
\mathrm{t}\end{array}$ & 948,00 & 1005,00 & 353,00 & $-1,73$ & $\mathbf{0 , 0 8}$ \\
\hline Readiness & 1239,00 & 714,00 & 308,00 & 2,37 & $\mathbf{0 , 0 2}$ \\
\hline Satisfaction & 1232,00 & 721,00 & 315,00 & 2,27 & $\mathbf{0 , 0 2}$ \\
\hline Regulativity & 932,00 & 1021,00 & 337,00 & $-1,96$ & $\mathbf{0 , 0 5}$ \\
\hline Modality & 980,00 & 973,00 & 385,00 & $-1,28$ & 0,20 \\
\hline
\end{tabular}

Significant differences are obvious in relation to such components of the factor structure as "Readiness", "Satisfaction", "Regulativity", as a statistic tendency, the difference in the "Estrangement" factor was also detected.

\section{Conclusion}

As a result of the factorial analysis procedure, six factors were detected in the psychological structure of regional identity experience representation: "Activity" (the event connected with the experience of regional identity wasn't complete, but the subjects demonstrated determination, energy, enthusiasm), "Estrangement" (the event was connected with daily routine and ended negatively that entailed isolation; high activity was shown by people involved in the event experienced by the subject), "Readiness" (the event was followed by high emotional pressure, high motivation and activity of the subjects; on the one hand, they felt suspense and, on the other hand, were interested in obtainment of new knowledge), "Satisfaction" (the event happened in the territory of residence, ended positively, was characterized with high personal importance for the subjects and led to their integration with the region), "Regulativity" (the event was connected with the sphere of health and led to assimilation of some rules regulating the subjects' behavior, was accompanied by disappointment and surprise as a cognitive state of the personality; the time of the event becomes especially significant), "Modality" (the event occurred within the region borders, was followed by a condition of reverie, had a cognitive (epistemic) modality as a learning opportunity [8].

Proceeding from the two samples compared, the following peculiarities of the childhood regional identity experience were revealed. Those who experienced regional identity in the childhood are more deeply involved in the experience, without isolating themselves from the internal and external circumstances that entailed the experience; they demonstrate a more positive attitude and are open to such experience. Such a personality demonstrates a higher level of readiness to reproduction of this experience in life and feels satisfied with the psychological interconnection with the region of residence. Herewith, one can see that such a personality is characterized with lower rates within the regulativity factor. That proves a more unaffected representation of the experience and a low level of its reflexivity that is connected to the peculiarities of the experience fixation. It appears that regulativity of the regional identity experience serves as a resource for its formation in youth. The obtained results can create the basis of a psychology pedagogy program of children's regional identity formation (including migrant children) realized in educational organizations.

Research was executed at the expense of a grant of the Russian scientific foundation (project no. 16-18-02102)

\section{References}


1. M. Antonsich, E.Holland, Eur.Urb. and Reg.Studies, 21(2), 206-221 (2014)

2. R. Asun, C. Zuniga, Est. de Psicol, 34, 95-100 (2013)

3. J. Bruner, Child's talk (Norton, New York,1983)

4. J. Bruner, Crit. Inq. 18, 1-21 (1991)

5. J. Bruner, The Culture of Education (Harvard Univers. Press, Cambridge, 1996)

6. W. de Vit Cary, Jour. of Cult.Geogr. 30 (1), 120-144 (2013)

7. F. Charton-Vachet, C. Lombart. Rech. et App. en Market, 30(1), 50-75 (2015)

8. M. Epstein, Philosophy of the possible. (Aleteya, Saint Petersburg, 2001)

9. M. Farukshin, Ethnopolitology. (Kazan University, Kazan, 2014)

10. Y. Golovnyova, Labirint. 5, 42-50 (2013)

11. O. Kirichek, Act. Probl.of Psychol. Knowl. 1, 3-9 (2012)

12. M. Krylov, Regional identity in European Russia. (Noviy chronograph, Moscow, 2010).

13. M. Levandovsky, Quest. of Psychol. 5, 138-142 (1980)

14. D. Massey, Space, place and gend. 146-156 (1994)

15. A. Nasledov, Mathematical methods of psychological research. (Rech, Saint Petersburg, 2004)

16. M. Nazukina, Regionol. 4, 28-35 (2011)

17. A. Paasi, K. Zimmerbauer, Treb. de la Soc. Catalana de Geogr. 2, 163-178 (2011)

18. D. Santana, H. Carrasco, C. Estrada, Est. de Psicol. 34, 83-88 (2013)

19. E. Schubach, J. Zimmermann, P. Noack, Europ. Journ. of Personal. 30, 189-200 (2016)

20. K. Uberla, Factor analysis. (Berlin-Heidelberg, New York, 1977)

21. T. Valieva, Strategies of pedagogical experience fixation in individual psychological culture of educator. Thesis for the cand.'s degree. (Yekaterinburg, 2010)

22. D. Zamyatin, Identity and territory. (IMEMO RAN, Moscow, 2010)

23. G. Zhigunova, Social identity of juvenally challenged persons. (Direct-Media, Moscow - Berlin, 2014).

24. C. Zuniga, R. Asun, Revist. de Psicol. Social. 25, 215-230 (2010) 